\title{
Carbon Sequestration under Saffron (Crocus sativa) Cultivation as Influenced by Different Levels of Organic Manure and Inorganic Nitrogen
}

\author{
Nayar Afaq Kirmani*, Javid Ahmed Sofi ${ }^{1}$, M. Ayub Bhat, Shabira Bangroo, Juvaria Jeelani ${ }^{2}$ \\ Division of Soil Science, SKUAST-K, Shalimar, Srinagar-190025, Jammu and Kashmir, India \\ ${ }^{\prime}$ Research Centre for Residue and Quality Control Management, SKUAST-K, Shalimar, Srinagar-190025, \\ Jammu and Kashmir, India \\ ${ }^{2}$ Division of Soil Science, FOA, SKUAST-K, Wadoora, Barmulla-193101, Jammu and Kashmir, India
}

\begin{abstract}
The effect on carbon sequestration under saffron (Crocus sativa) cultivation as influenced by different levels of organic manure and inorganic nitrogen was investigated in a field experiment at Dryland (Karewa) Agriculture Research Station, Budgam, Kashmir. The farm yard manure was applied at 0,30 and $60 \mathrm{t} \mathrm{ha}^{-1}$ and inorganic nitrogen at 0,45 and $90 \mathrm{~kg} \mathrm{ha}^{-1}$, respectively along with Azotobacter. The organic carbon content was recorded at three stages, immediately after flowering (Oct-Nov), during vegetative growth stages in (Feb- March) and (April-May), respectively. The pooled data indicated that at stage I, there was a significant increase in the organic carbon in the soil with the application of maximum amount of FYM and nitrogen. The mean organic carbon content of the soil increased from $9.22 \mathrm{~g} \mathrm{~kg}^{-1}$ to $15.34 \mathrm{~g} \mathrm{~kg}^{-1}$ when FYM was applied in conjugation with inorganic nitrogen. However, the highest and significant organic carbon $\left(17.50 \mathrm{~g} \mathrm{~kg}^{-1}\right)$ was observed in the treatment in which nitrogen was applied at $90 \mathrm{~kg} \mathrm{ha}^{-1}$ and FYM at $60 \mathrm{t}$ $\mathrm{ha}^{-1}$ an increase of 156.9 per cent over the control $\left(6.81 \mathrm{~g} \mathrm{ha}^{-1}\right)$. Similar trends were also observed at stage II and III, respectively. However, the effect of Azotobacter was found significant only at stage-III.
\end{abstract}

Key words: Azotobacter, carbon sequestration, FYM interaction, nitrogen, saffron

\section{Introduction}

Saffron (Crocus sativus L.) is the most expensive spice, and is regarded as one of the economy regulating factor in agriculture sector for the development of Jammu and Kashmir State. However, the crop has a very low harvest index (stigma/biomass) (Molafilabi 2004) and hence for increasing the yield of the crop is very important which can be realized by following improved cultural methods (Munshi 2002;

*Corresponding author: (Email: afaqnayar@gmail.com)
Fernandez 2004). Saffron is a perennial crop with a life span of 4-5 years and it requires an adequate amount of nutrients. In traditional saffron culture, no fertilizers are applied to the crop, except initial application of 5-10 tonnes farm yard manure at planting, the field is left even for 10-15 years or even more, without any external chemical fertilizer.

In Kashmir, the crop is grown in Pampore belt under rainfed conditions with blanket/ no fertilizer application. The subsistence agriculture without fertilizer or organic matter addition depleted the 
nutrients and organic carbon in these soils. Due to the deterioration of soil health, the quantity and quality of saffron yield have remarkably declined during the last decade (Nehvi et al. 2004 and Behdani 2005 ). Organic manures improve physical, chemical and biological properties of soils besides carbon sequestration (Sofi et al. 2009) that improves crop yields. The bio-fertilizers, which are low cost and eco-friendly, have tremendous potential for supplying the nutrients which can reduce the chemical fertilizer dose by $25-50 \%$ (Vance 1997).

For carbon credits to be meaningful, sustained carbon sequestration for decades or longer periods is required. It has been shown that improved land management could result in sequestration of a substantial amount of carbon in the soils within decades, and therefore, can be an important option in reducing atmospheric $\mathrm{CO}_{2}$ concentration (Upadhyay et al. 2005). Keeping this in view and the absence of any standardized nutritional protocol for saffron in the Kashmir, India, the present study was conducted under the project "Standardization of Integrated Nutrient Management for Saffron" in Dryland (Karewa) Agriculture Research Station, Budgam, with an active support and assistance of ICAR under its flagship programme-"Horticulture Mini-Mission-HTMM2.22".

\section{Materials and Methods}

A field experiment was conducted at Dryland (Karewa) Agriculture Research Station, Budgam for 4 years (2007-2010) to study the effect of different fertility management practices on saffron and the results were further tested in farm trials under one of the flagship programmes of NAIP during 2009-2014. The landform of the farm was broad valley with arable land use, having mid to high altitude, temperate agro-climatic zone, moist sub-humid, agro-ecological zone with growing period of 150-210 days (Rana et al. 2000; Kirmani et al.
2013). The annual precipitation varies from 600- 900 $\mathrm{mm}$. The maximum precipitation is received in the form of snow during winter. Sub-zero temperatures are recorded from November to January. The mean maximum temperatures reach to $24.5^{\circ} \mathrm{C}$ in the month of July and mean minimum temperature reaches minus $2.0^{\circ} \mathrm{C}$ in the month of January. Moisture regime is udic with mesic temperature regime (Kirmani 2005).

The experiment was conducted in a randomized block design with three replications. Farmyard manure was applied at 0,30 and $60 \mathrm{tha}^{-1}$ and inorganic nitrogen at 0,45 and $90 \mathrm{~kg} \mathrm{ha}^{-1}$, respectively along with Azotobacter. The organic carbon content was recorded at three stages, immediately after flowering (Oct.-Nov.), during vegetative growth stages (Feb.- March) and (April- May), respectively. Soil texture was clay loam with a high plasticity. The soil samples collected from each treatment were analysed for various physical and chemical properties like soil reaction and electrical conductivity in 1:2.5, soil: water suspension (Jackson 1973). Organic carbon was determined by the wet digestion method of Walkley and Black (1934) as modified by Walkley (1935). The initial status of N, P and $\mathrm{K}$ of soil was $210.28 \mathrm{~kg} \mathrm{ha}^{-1}, 19.57 \mathrm{~kg} \mathrm{ha}^{-1}$ and 298.12 $\mathrm{kg} \mathrm{ha}^{-1}$, respectively. The data was statistically analysed using statistical software 'MINITAB'.

\section{Results and Discussion}

The $\mathrm{pH}$ of the experiment site ranged from 6.7 to 7.65 and $\mathrm{EC}$ was low with a mean value of $0.11 \mathrm{dSm}^{-1}$. Based on the means of the pooled data, the results indicated that at stage I, there was a significant increase in the organic matter content in the soil with the increase in the application of FYM from 0 to $60 \mathrm{tha}^{-1}$ and $\mathrm{N}$ from 0 to $90 \mathrm{~kg} \mathrm{ha}^{-1}$ (Fig. 1). There was an increase in the mean organic carbon content of the soil from $9.22 \mathrm{~g} \mathrm{~kg}^{-1}$ to $15.34 \mathrm{~g} \mathrm{~kg}^{-1}$ when FYM was applied in conjugation with inorganic nitrogen. 


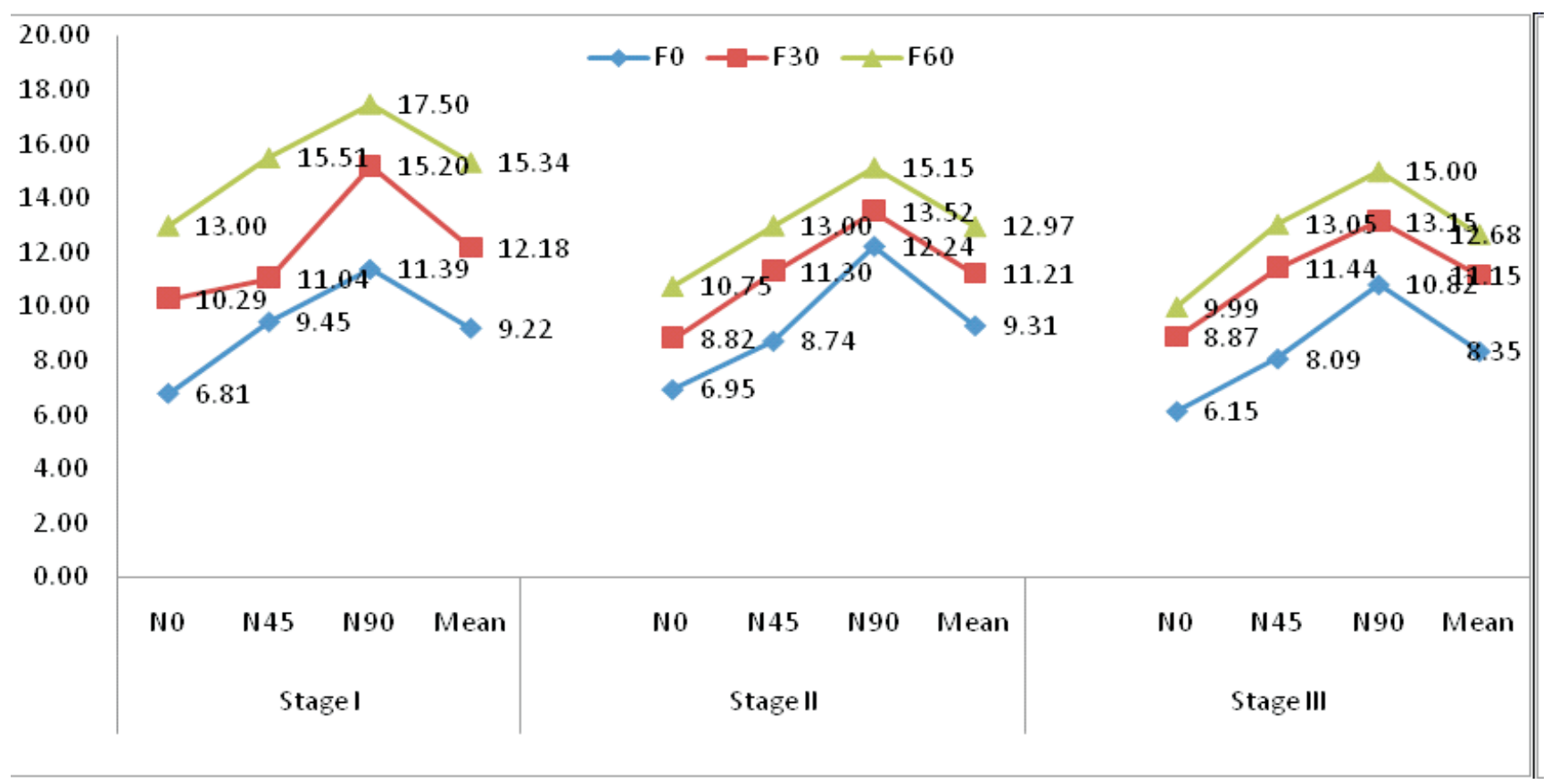

Fig. . $\quad$ Organic Carbon ( $\mathrm{g} \mathrm{kg}^{-1}$ soil) content as influenced by FYM and Nitrogen at different growth stages. $\mathrm{CD}(\mathrm{P}=0.05)$ for $\mathrm{N}$ and $\mathrm{F}=0.2,0.12$ and 0.15 for three stages, $\mathrm{N} \times \mathrm{F}=0.32,0.21$ and 0.26 for stage $\mathrm{I}$, stage II and stage III respectively.

However, the highest and significant organic carbon $\left(17.50 \mathrm{~g} \mathrm{~kg}^{-1}\right)$ was observed in the treatment in which FYM was applied @60 tha ${ }^{-1}$ and nitrogen@90 kg $\mathrm{ha}^{-1}$, an increase of 156.97 per cent over the control (6.81 $\left.\mathrm{g} \mathrm{ha}^{-1}\right)$. Such increase was also noticed at stage II and Stage III, wherein the mean organic carbon content increased from $9.31 \mathrm{~g} \mathrm{~kg}^{-1}$ to $12.97 \mathrm{~g} \mathrm{~kg}^{-1}$ and $8.35 \mathrm{~g} \mathrm{~kg}^{-1}$ to $12.68 \mathrm{~g} \mathrm{~kg}^{-1}$, respectively. Their interaction effect has shown a significant increase of 117.98 and 143.90 per cent which corresponds to $15.15 \mathrm{~g} \mathrm{~kg}^{-1}$ and $15.00 \mathrm{~g} \mathrm{~kg}^{-}$ ${ }^{1}$ from their respective control of $6.95 \mathrm{~g} \mathrm{~kg}^{-1}$ and $6.15 \mathrm{~g} \mathrm{~kg}^{-1}$ at both the stages. The increase in the organic carbon content in soil with the increase in FYM has already been documented (Fang et al. 2005; Majmudar et al. 2008; Kirmani et al. 2010; Sofi et al. 2013). There has been a slight decrease in OC from stage I to stage III might be due to the seasonal change in crop from Oct.-Nov. in stage I and April-May in stage III due to less decomposition rates owing to low in the valley (Sofi et al. 2009; Javaria and Khan 2011).
The effect of Azotobacter on the organic carbon content was also observed in conjugation with the interaction of FYM and nitrogen. The results revealed that the mean effects of N, FYM and Azotobacter and their interaction were non-significant in stage I and stage II (Fig. 2 and 3) while the effect of Azotobacter was significant only at stage III (Fig. 4). Among the interaction effects, FYM and $\mathrm{N}$ were found to be significant at all the stages of growth. The highest organic carbon content of $13.93 \mathrm{~g} \mathrm{~kg}^{-1}$ was observed when FYM at $60 \mathrm{t} \mathrm{ha}^{-1}$ was applied with Azotobacter which showed an increase of 58.29 per cent over its control of $8.80 \mathrm{~g} \mathrm{~kg}^{-1}$. Similarly, $11.42 \mathrm{~g} \mathrm{~kg}^{-1}$ of organic carbon was observed when higher levels of FYM was applied without Azotobacter which had 44.55 per cent increase over its respective control of $7.90 \mathrm{~g} \mathrm{~kg}^{-1}$. There was significant increase in the overall effect of Azotobacter on organic carbon from $9.81 \mathrm{~g} \mathrm{~kg}^{-1}$ to 11.65 $\mathrm{g} \mathrm{kg}^{-1}$ (18.75 per cent increase). The application of Azotobacter leads to increase in soil organic carbon and improves soil health (Schuman et al. 2002; Kirmani et al. 2014; Kashyap et al. 2017). 


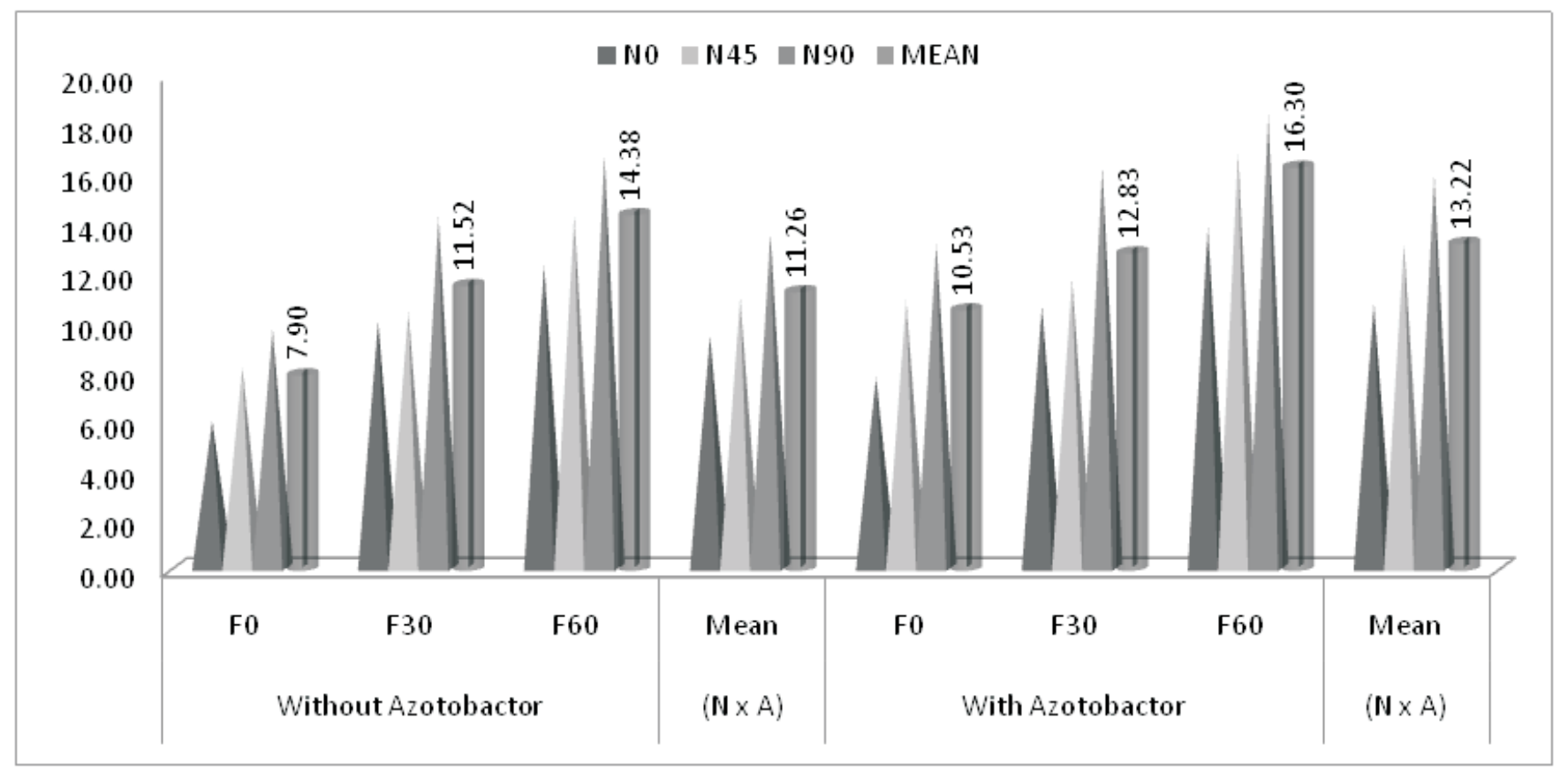

Fig. . Organic Carbon ( $\mathrm{g} \mathrm{kg}^{-1}$ soil) content at growth stages- $\mathrm{CD}(\mathrm{P}=0.05)$ for $\mathrm{N}$ and $\mathrm{F}=0.2, \mathrm{~N} x \mathrm{~F}=0.32$, effect of Azotobacter N x A, F x A and N x F x A were found non-significant.

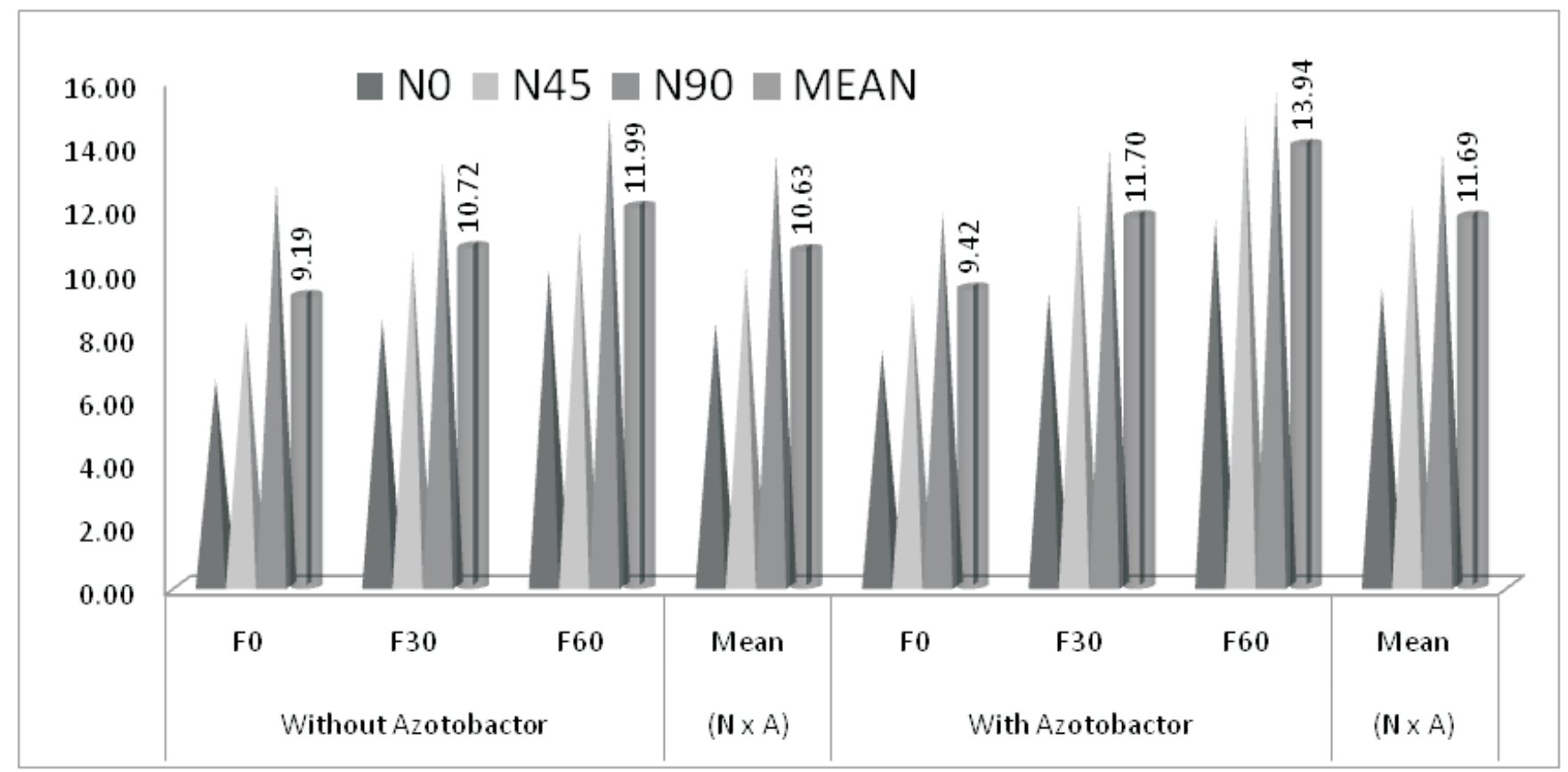

Fig. . Organic Carbon ( $\mathrm{g} \mathrm{kg}^{-1}$ soil) content at growth stages II. $\mathrm{CD}(\mathrm{P}=0.05)$ for $\mathrm{N}$ and $\mathrm{F}=0.15, \mathrm{~A}=0.12, \mathrm{~N} x \mathrm{~F}=0.26$, effect of N x A, F x A and N x F x A were found non-significant. 


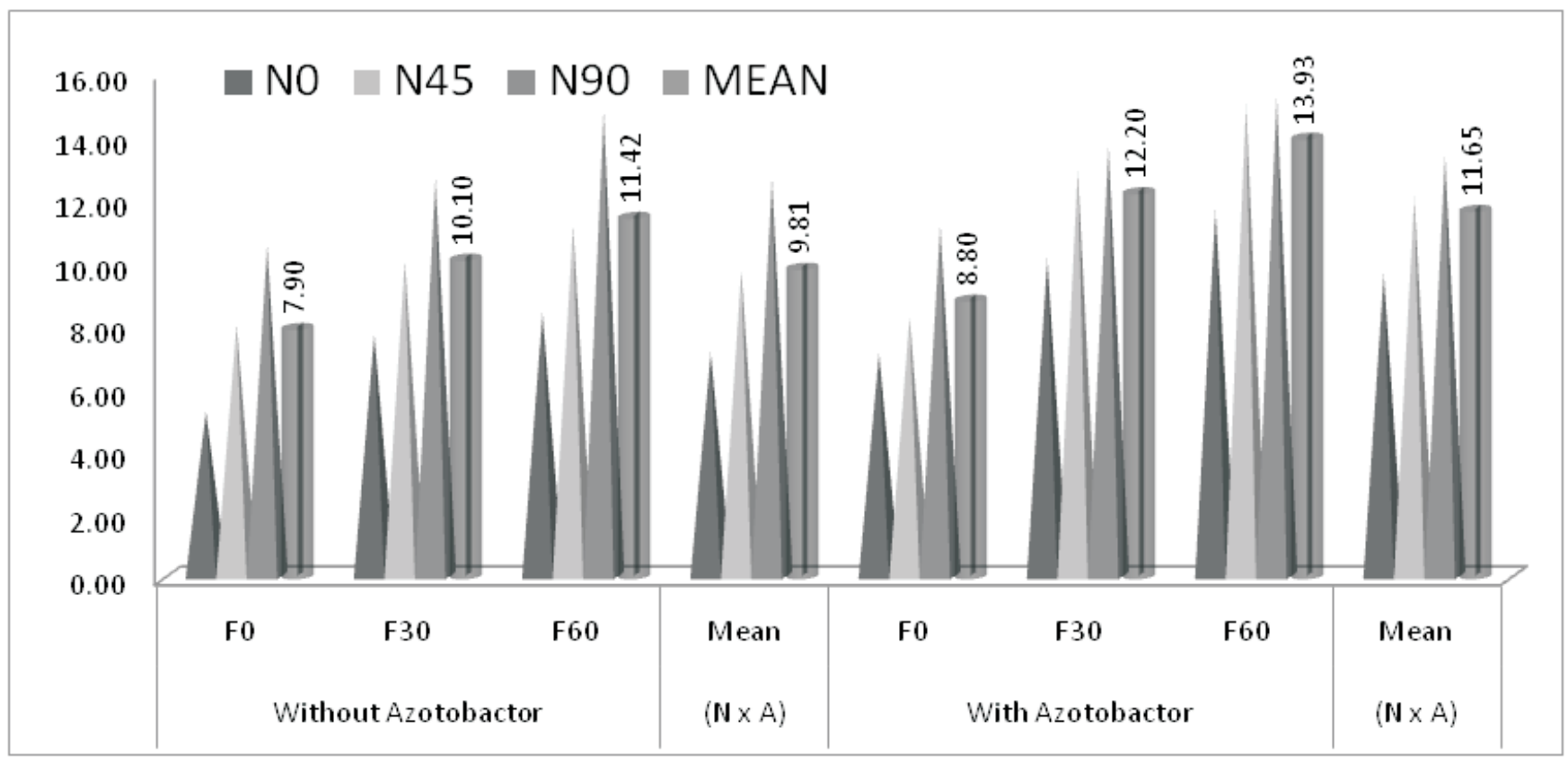

Fig. . Organic Carbon ( $\mathrm{g} \mathrm{kg}^{-1}$ soil) content at different growth stages-III effect of Azotobacter N x A, F x A and $\mathrm{N} \times \mathrm{F} \times \mathrm{A}$ were found significant.

The impact of Azotobacter was statistically significant on corm production but non-significant on saffron yield. There was positive influence of INM on physico-chemical properties of soil and available forms of NPK. The impact of integrated phosphorous and potassium management on saffron yield has also been recorded (Kirmani et al. 2013).

\section{Conclusion}

It can be inferred that different levels of organic manure and inorganic nitrogen have positive impact on carbon sequestration. There was a reduction in the rates of soil organic carbon depletion due to the application of FYM with inorganic nitrogen. It was also observed that any modification in land use or management practice can bring about the change in soil carbon stocks. Azatobacter was found to increase the organic $\mathrm{C}$ content in soil upto some extent. The minimal use of chemical fertilizers is found to affect the quantity and quality of the saffron yield in the long term.

\section{Acknowledgement}

The authors are grateful to Indian Council of Agricultural Research, New Delhi for providing financial assistance, through their Horticulture Mini Mission programme, to carry out this investigation.

\section{References}

Behdani, M., Koocheki, A., Nassiri, M. and RezvaniMoghaddam, P. (2005). Evaluation of quantity relations between yield and nutrient consumption in saffron: on farm study. Journal of Iranian Field Crop Research 3, 1-14.

Fang, C., Smith, P., Moncrieff, J.B. and Smith, J.U. (2005). Similar response of labile and resistant soil organic matter pools to changes in temperature. Nature 433, 57-59.

Fernández, J.A. (2004). Biology, biotechnology and biomedicine of Saffron. In 'Recent Research Development in Plant Sciences-2' (Eds. J.A. Fernández) pp.127-159. (Research Signpost, Trivandrum, India). 
Jackson, M.L. (1973). 'Soil Chemical Analysis'. (Prentice Hall of India Private Limited: New Delhi).

Javaria, S. and Khan, M.Q. (2011). Impact of integrated nutrient management on tomato yield quality and soil environment. Journal of Plant Nutrition 34, 140-149.

Kashyap, L., Reddy, V.N. and Tiwari, A. (2017). Effect of integrated nutrient management practices effect on carbon sequestration, carbon stock, plant growth parameters and economics of cauliflower. International Journal of Current Microbiology and Applied Sciences 6, 14071415.

Kirmani, N.A. (2005). Characterization, classification and development of lacustrine soils of Kashmir valley. Ph. D Thesis submitted to Sher-eKashmir University of Agricultural Sciences and Technology of Kashmir, Shalimar. (unpublished)

Kirmani, N.A., Sofi, J.A., Bhat, M.A., Haq, S.A. and Bhat, M. I. (2010). Effect of

FYM, nitrogen and Azotobacter on carbon sequestration under saffron (Crocus

sativa) cultivation. In 'Proceedings of $2^{\text {nd }}$ International Conference on Climate Change and Sustainable Management of Natural Resources'. (5 th $-7^{\text {th }}$ December, ITM University, Gwalior, India).

Kirmani, N.A., Wani, M.A. and Sofi, J.A. (2013). Characterization and classification of Alfisols under lesser Himalayan temperate region. Agropedology 23, 118-121.

Kirmani, N.A., Sofi, J.A., Bhat, M.A. and Ansar-ul-haq, $S$. (2014). Sustainable saffron production as influenced by integrated nitrogen management in typic hapludalfs of NW Himalayas. Communication in Soil Science and Plant Analysis 45, 653-668.

Majmudar, B., Mandal, B., Bandyopadhyay, P.K., Gangopadhyay, A., Mani, P.K., Kundu, A.L. and Mazumdar, D. (2008). Organic amendments influence soil organic carbon pools and ricewheat productivity. Soil Science Society of America Journal 72, 775-785.
Molafilabi, A. (2004). Experimental finding of production and eco-physiological aspects of saffron (Crocus sativus L.). Acta Horticulturae 650, 195-200.

Munshi, A.M. (2002). Marketing and trade mechanism of saffron in Jammu \& Kashmir. In 'Proceedings of National Seminar cum Workshop on Development of Saffron. pp. 8388. (Kashmir, India).

Nehvi, F.A., Agarwal, S.G., Verma, M.K., Dar, S.A., Mir, Z.A., Nabi, N. and Allie, B.A.

(2004). Technological innovations for saffron production. In 'Proceedings of National Symposium on Enhancing Sustainable Agricultural Productivity in Hill and Mountainagro Ecosystem'. pp. 58-67. $\left(10^{\text {th }}-12^{\text {th }}\right.$ August, Dehrudun, Uttaranchal, India).

Rana, K.P.C., Walia, C.S., Sidhu, G.S., Singh, S P., Velaytham, M. and Sehgal, J. (2000). Soils of Jammu and Kashmir: Their kinds, distribution, characterization and interpretation for optimum land use. National Bureau Soil Survey and Land Use Planning, Technical Publication No. 62, Nagpur.

Schuman, G.E., Janzen, H.H. and Xerrick, J.E. (2002). Soil carbon dynamics and potential carbon sequestration by range lands. Environment Pollution 116, 391-396.

Sofi, J.A, Kirmani, N.A., Haq, S.A. and Chesti, M.H. (2009). Integrated use of organic manures and inorganic nitrogen for sustaining productivity of saffron and soil health under Kashmir conditions. In 'Proceedings of $3^{\text {rd }}$ International Symposium on Saffron'. (20$23^{r d}$ May, Krokos, Kozani, Greece).

Sofi, J.A., Kirmani, N.A., Sharma, V.K., Ansar-ul-Haq, S. and Chesti, M.H. (2013). Effect of integrated nutrient management in saffron. Indian Journal of Horticulture 70, 274-78.

Upadhyay, T.P, Sankhayan, P.L. and Solberg, B. (2005). A review of carbon sequestration dynamics in the Himalayan region as a function of land-use change and forest/soil degradation with special reference to Nepal. Agriculture, Ecosystems and Environment 105, 449-465. 
Vance, C.P. (1997). Enhanced agricultural sustainability through biological nitrogen fixation. In 'Biological Fixation of Nitrogen for Ecology and Sustainable Agriculture'. (Eds. A. Legocki, H. Bothe and A. Pühler) pp. 179-186. (SpringerVerlag, Berlin).
Walkley, A. (1935). An estimation of methods for determining organic carbon and nitrogen in soils. Journal of Agriculture Science 25, 589609.

Walkley, A. and Black, J.A. (1934). An examination of the method for determining soil organic matter and a proposed modification of the chromic acid titration. Soil Sciences 37, 29-39. 